\title{
Editorial: COVID-19 Crises and Higher Education in Nepal
}

COVID-19 pandemic that propagated from December 2019 has alarmingly impacted all sectors globally, with over 66 million infections and 1.5 million human deaths as of November 2020 (Worldometer). It has led to serious setback of the overall global economy including tourism, socioeconomic development, human health and wellbeing. Likewise, the education sector has suffered negatively due to the pandemic. Globally, it is estimated that about 1.25 billion students are affected by the lockdown (UNESCO 2020). Similarly, UNDP reported that 86 percent of primary school children are affected or bereft of education in developing countries due to the pandemic (UNDP 2020). The United Nation's Sustainable Development Goal 4 promotes inclusive and equitable quality education and lifelong learning opportunities for all. It has further expressed ensuring equal access to affordable and quality technical, vocational, and tertiary education, including at university levels for all women and men. In the same line, The Constitution of Nepal 2015 stipulates access to quality education as the fundamental right of its citizens. However, like other least developed countries, Nepal faces high social and economic vulnerability leading to structural weaknesses, health emergency and weakening of educational system because of the pandemic.

In Nepal, the Government imposed a lockdown on 24th March 2020 as a measure to contain the deadly virus. Therefore, all the schools and universities were closed to avoid face-to-face teaching, and different e-learning platforms were created to engage students in the learning process. However, higher education receives low priority from the government in Nepal with inadequate allocation of resources and poor governance. The situation was further exacerbated by the pandemic, which caused difficulties in running regular classes, exams, and field exercises on time. The traditional physical classes are turned into online classes challenging their effectiveness due to unavailability of appropriate effective technology and skilled human resources. Furthermore, students from remote parts of the country face problems accessing education through online platforms. The most affected by current mode of education were students, generally from rural areas and poor economic status, unable to afford internet devices and services.

The Institute of Forestry (IOF) of Tribhuvan University, since 1972, is committed to offer Bachelors, Masters and PhD level education in forestry and natural resource management through its three campuses in Hetauda, Pokhara and Kathmandu (www.iof.edu.np). Preliminary study on the effectiveness of the online classes at IOF showed ca. 50\% attendance at the Bachelor's level and much better at the Master's level primarily due to small numbered class size. Besides, locational, technological advancement and competent internet facility benefit urban over poor rural dweller's access to quality education. Similarly, inadequate infrastructure, technology and trained human resources with limited government funding are barriers to transforming online teaching in the universities effective. Current scenario poses 
grave danger of Nepal's higher education's getting deteriorated further in the future. This may defeat Nepal's commitment and contribution to achieve SDG Goal 4. Like a silver line in the black cloud, the pandemic availed opportunity and forced the policy makers, university administrators and educationists to reform higher education in Nepal. It is high time to revise and adopt appropriate and affordable curricula, pedagogy, and evaluation methods. Overall, higher education in Nepal is at a crossroad to balance the needs of both urban and rural dwellers vis-à-vis inclusive and equitable hybrid approach to suit the country's social, economic and geopolitical situation.

Editorial board, November 2020

DOI: https://doi.org/10.3126/forestry.v17i0.33618

\section{Literature Cited:}

UNESCO. 2020. The socio-cultural implications of COVID-19.

UNDP. 2020. The human development report. United Nations Development Programme. USA. 